examples of "electric phenomena"; and Imoda an author of a book on psychic photography.

Apart from criticisms of this kind, the book is likely to be of great service to those who wish to gain a general view of some particular aspect of psychical research or to revise a previous acquaintance. The author must certainly be congratulated on the trouble he has taken, although he would be well advised to omit certain of the photographs in any later edition. One of these is instructive. It shows the medium Rudi Schneider when supposed to be controlled by two observers. His right hand is apparently not held in any way. It is a good example of what occurs in 'psychic science'.

\section{A Description of some Trees, Shrubs and Lianes of} Southern Rhodesia. By E. C. Steedman. Pp. xxi + $191+92$ plates. (Gwelo, Southern Rhodesia: Miss E. C. Steedman, Norfolk Farm, 1933.) $7 s .6 d$.

Miss Steedman is to be congratulated on having produced a book on the trees, shrubs and lianes of Southern Rhodesia, which should be of great service to residents in the colony and should stimulate an interest in the vegetation of the country and also, it is to be hoped, serve a useful purpose in arresting the destruction of the indigenous timber.

Miss Steedman has worked under considerable difficulties, being away from sources of botanical literature, and, in consequence, some errors in the nomenclature of the plants to which she refers have crept in. This, however, is a minor point which can easily be set right when she has had an opportunity of consulting authorities and literature, should a second edition of the book be called for.

Thanks to the keys and descriptions, it should be possible for anyone interested in plants to be able to identify the native species, and this will be considerably facilitated by the line drawings which are, on the whole, quite useful, though in some cases they have suffered a little in reproduction.

From the purely botanical point of view, some criticisms can be offered, but the main point about the book is its value to residents in Southern Rhodesia. This is enhanced by the inclusion of the native names of the trees and shrubs wherever it has been found possible to assign them to a definite species.

As the work of an amateur with a real love of her subject, the book certainly deserves high commendation.

A Standard Classified Nomenclature of Disease. Compiled by the National Conference on Nomenclature of Disease. Edited by Dr. H. B. Logie. Pp. xvii +701 . (New York: The Commonwealth Fund; London: H. K. Lewis and Co., Ltd., 1933.) $21 s$.

THE National Conference (of the United States of America) on Nomenclature of Disease was formed with the object of solving the confusion due to the absence of a standard nomenclature of pathological conditions. It has now produced the system described in this book, a dual method of classifying disease, based on the two features of topography and etiology. The topographical classification gives a code number to every region of the body in which disease can be clinically located; the first numeral indicates the body system, the second the organ, and the third the part of the organ involved. The etiological classification similarly divides all causal factors into groups, which are further subdivided. Any disease or injury has thus a number indicating location hyphened to another indicating cause. The system also allows expression in symbols of obscure, undiagnosed or partially diagnosed conditions.

The book can be strongly recommended to the records departments of hospitals, and as the method advocated requires accurate expression of a diagnosis, its adoption would do immense good in stimulating precise thinking and avoidance of ill-defined terms on the part of clinicians.

A Bibliography of Differential Fertility: in English, French and German. Edited by Eldon Moore on behalf of Commission II of the International Union for the Scientific Investigation of Population Problems. Pp. vi +97 . (London: Dr. E. C. Rhodes, London School of Economics, 1933.) $2 s$.

THE compiler of this book is not a biologist but a journalist who, like many other intelligent laymen, has been attracted by the lure of biology and the problems which it involves. For a considerable time he acted as editor of the Eugenics Review, the organ of the Eugenics Society. He has produced in this book a most valuable compilation of papers and books dealing with the problems of fertility both in man and animals.

An Elementary Introduction to Physics: Descriptive, Experimental and Historical. By Edgar Booth. Pp. $465+$ xvi. (Glebe, N. S. W. : Australasian Medical Publishing Co., Ltd. ; London: H. K. Lewis and Co., Ltd., 1933.) $5 s$. net.

A воOK from Australia is to be welcomed, as it is likely to put forward fresh points of view which give hints to teachers of elementary physics in Great Britain. This book is quite elementary in character and practical in type, and the author has avoided the mistake of introducing the ideas of modern physics at this early stage.

Précis d'électricité théorique. Par Dr. Léon Bloch. Deuxième édition, revue et corrigée. Pp. vii + 476. (Paris: Gauthier-Villars et Cie., 1933.) 50 francs.

Thrs treatise gives an account of classical electrical theory, with modern notation and the use of vector analysis where necessary. It is comprehensive and clear and ends with two important chapters, one on the electrodynamics and the other on the optics of bodies in motion. 